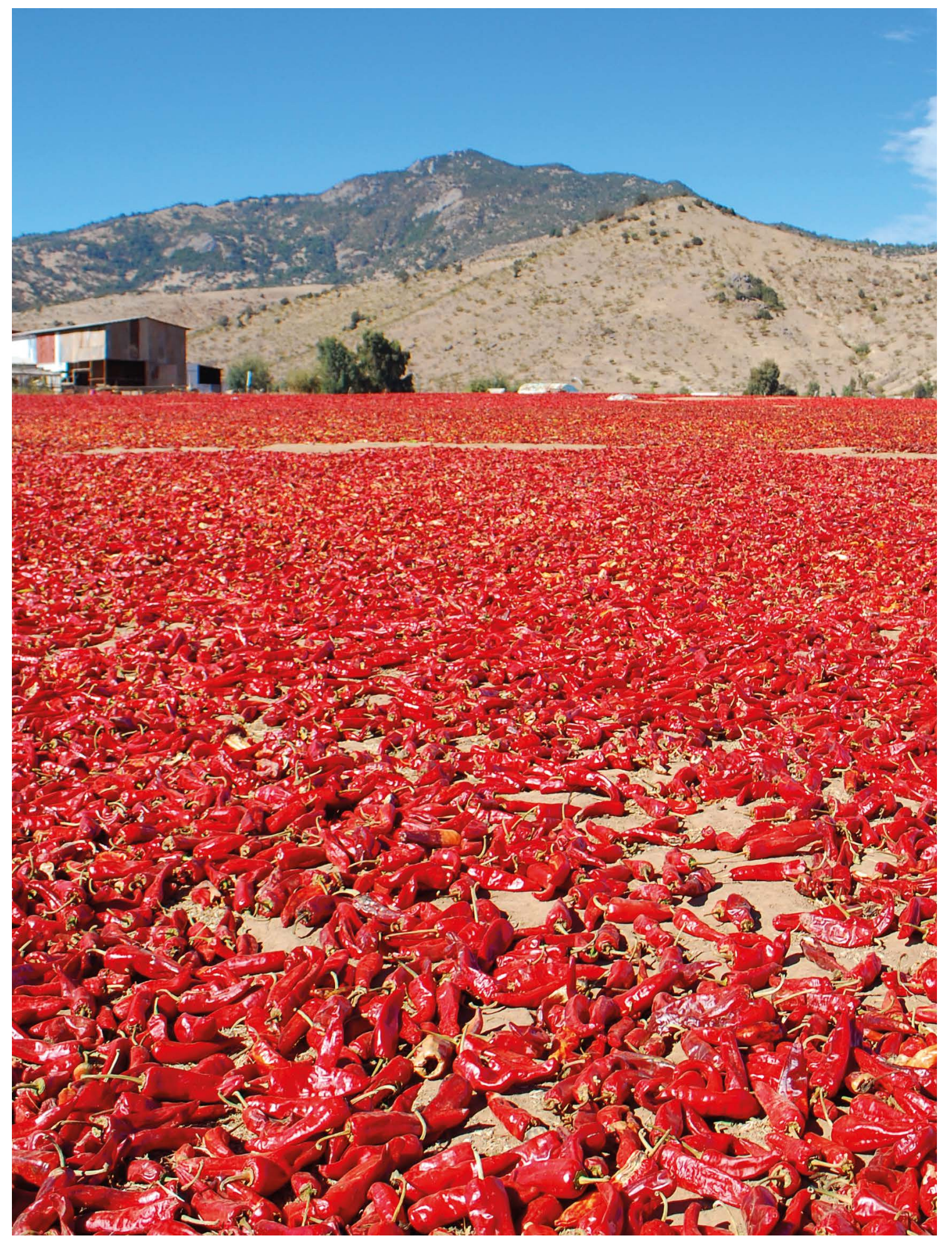



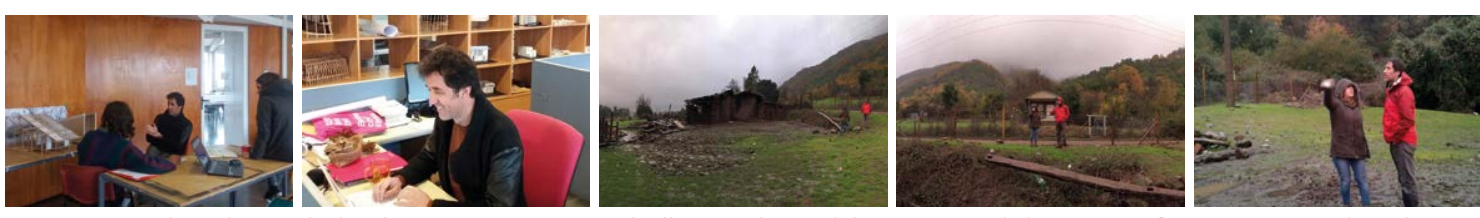

Secuencia: Un día en la Escuela de Talca, en mi escritorio, en el Taller y en el Río Achibueno, visitando lugares para futuros proyectos de titulación Fotos: Diego Espinoza, Matias Jauregui, Belén Verdugo y Cecilia Silva

\title{
HABITAR LA ORILLA. DE LOS LUGARES COLECTIVOS Y LA ESTRUCTURA DE LA RURALIDAD EN EL VALLE CENTRAL DE CHILE: UNA REVISIÓN DE TIPOS Y CASOS'
}

\author{
INHABITING THE EDGE. ON THE COLLECTIVE PLACES AND STRUCTURE OF RURALITY \\ IN CHILE'S CENTRAL VALLE: A REVIEW OF TYPES AND CASES'
}

Eduardo Aguirre León ${ }^{2}$

RESUMEN

El propósito de este artículo es llevar a cabo una lectura de ciertos lugares rurales en el Valle Central de Chile, aquellos que surgen y se desarrollan fuera de las políticas oficiales y que, sin embargo, son capaces de dar cuenta de su territorio, casi siempre de manera espontánea. Se afirma, a manera de hipótesis, que estos lugares emergen y están caracterizados por una condición de marginalidad, relacionada con el hecho de desarrollarse en los bordes del proceso de modernización de este territorio. Una revisión de casos -obras desarrolladas en el Taller de Titulación de la Escuela de Arquitectura de la Universidad de Talca-, permite elaborar una reflexión sobre la capacidad de la arquitectura para activar el potencial público subyacente en ellos. A partir de una serie de intervenciones realizadas en un contexto académico, proyecto y obra se constituyen en vehículo y método de investigación, por cuanto permiten develar estructuras físicas y culturales preexistentes; en definitiva, maneras de habitar el territorio.

Palabras clave: arquitectura rural, asentamientos rurales, patrimonio rural, espacio público, territorio.

\section{ABSTRACT}

The purpose of this text is to portray certain types of rural places in the Central Valley of Chile: those that emerge and develop outside of official policies and, nevertheless, are still able to represent the features of their territory, almost always in a spontaneous manner. It is hypothesized that these places arise and are characterized by a condition of marginality, related to the fact that they develop on the edges of this territory's modernization process. A review of some cases-projects created in the Graduation Workshop class at the University of Talca's School of Architecture enabled a reflection on the ability of architectural projects to activate their underlying potential to become public space. Based on a series of interventions carried out in an academic context, planned and built projects constitute the vehicles and methods of research. Thus, they made it possible to reveal preexisting physical and cultural structures - in short, ways of inhabiting the territory.

Keywords: rural architecture, rural settlements, rural heritage, public space, territory.

Artículo recibido el 27 de enero de 2017 y aceptado el 11 de junio de 2017 DOI: https://doi.org/10.22320/07196466.2017.35.051.06

[1] Este artículo se basa en resultados de investigación desarrollada durante el proceso académico del Taller de Titulación de la Escuela de Arquitectura de la Universidad de Talca, entre los años 2009 y 2016.

[2] Escuela de Arquitectura de la Universidad de Talca, Talca, Chile. eaguirre@utalca.cl 
"La periferia no es el lugar donde el mundo termina, sino que es el lugar donde el mundo se decanta"

Josef Brodskij

Recorrer el Valle Central de Chile $^{3}$ en un día cualquiera, yendo desde uno de sus pueblos hacia otro, es transitar en medio de un paisaje tan hermoso como raro. Esta característica provendría tanto de una falta de coherencia visual como de la vitalidad en la que coexisten órdenes agrícolas y suburbanos, plantaciones, caseríos, infraestructuras de riego y de caminos, agroindustrias y aserraderos, y un largo etcétera que conforma un paisaje cada vez más lejano del imaginario de la ruralidad que porfiadamente persiste desde la colonia. Se puede afirmar que se trata de un espacio lleno de contradicciones.

Esta condición ha sido descrita como una ruralidad quebrada, en la que aún se encuentran trazas del orden hacendal ${ }^{4}$ así como retazos del resultado de la reforma agraria ${ }^{5}$, unas y otros entrelazados con un nuevo proceso que revierte la reforma, concentrando la propiedad de la tierra en pocas manos y grandes paños, esta vez destinados a productos de exportación para mercados internacionales (Bengoa, 2008). Junto a ello, ocurre lo que podría llamarse la suburbanización del territorio, proceso caracterizado, entre otras cosas, por el incremento de conectividad, la parcela de agrado, el subsidio a la vivienda rural y la definición de nuevos límites urbanos.

De este modo, pareciera que acontece un proceso de transformación de identidad en el que la palabra ruralidad, con toda su connotación histórica ya no tuviera lugar, por cuanto lo que persiste es el imaginario de una condición en retirada, cercano a la nostalgia.

El desarrollo económico de las dos últimas décadas que ha situado al Valle Central de Chile en la economía global como un productor eficiente y competitivo de alimentos y vinos de exportación para ser consumidos por el primer mundo, ha sido determinante en su configuración espacial, inscribiéndose en lo que se ha dado en llamar "paisajes derivados"; aquellos producidos por prácticas coloniales diversas, entre ellas, las economías de enclave (Zusman, 2008).

Consecuencia de este proceso es el surgimiento de lo que ha sido denominado el "neolatifundismo" en el Chile Central; fenómeno asociado a la instalación de grandes empresas de producción de vinos de exporta-

[3] Entendemos por Valle Central la región comprendida entre la Angostura de Paine por el norte, el río Nuble por el sur, la cordillera de los Andes por el este y la franja costera por el oeste. Esta definición estaría dada más bien por el reconocimiento de una zona cultural con ciertos rasgos comunes, que por alguna definición geopolítica o geográfica. [4] El "orden hacendal" refiere al orden social y territorial establecido por la hacienda como institución que surge en la colonia, y que se proyecta hasta el siglo XIX.

[5] La "reforma agraria" refiere al proceso llevado a cabo entre los años 1960 y 1973, en el que se pretendía cambiar el orden hacendal y modernizar el campo. Para ello, se distribuyó a los campesinos tierras estatales y expropiadas, y se promovió la sindicalización campesina. 
ción, que progresivamente concentran paños de tierra y que, en ocasiones, construyen sobre los vestigios de la memoria del latifundio todo un imaginario turístico y comercial de lo rural asociado a ella (Bengoa, 2012) ${ }^{6}$.

Esta concentración de la propiedad de la tierra ha desdibujado en su trayecto tanto las subdivisiones prediales y los caminos de servidumbre, como las organizaciones sociales surgidas en el período de la reforma agraria. Del mismo modo, muchos campesinos se han desplazado a los centros poblados, convirtiéndose, muchas veces, en empleados "temporeros" de aquellas empresas a las que vendieran sus tierras.

Este proceso deja sus huellas en el paisaje a través de la proliferación de cercos y alambradas homogéneos y estandarizados, letreros de propiedad, advertencias de paso y portones de acceso a antiguos caminos de servidumbre. No sería equivocado plantear que se asiste a una progresiva privatización del territorio.

Completa este retrato del Valle la relación de interdependencia entre los poblados y el territorio rural'. Los asentamientos de esta zona se habrían establecido desde su origen a la manera de una expansión estatal del modelo de la hacienda. Con esta lógica, la construcción del paisaje urbanizado de esta región "se despliega desde la casa patronal hacia fuera, hacia las casas de los inquilinos, pasando por la capilla" (Mellado, 2013). Con posterioridad, la consolidación de la hacienda y el aumento de la población de inquilinos trajeron consigo el equipamiento, fruto de la obligación del Estado para con el resultado de ese crecimiento. Esto, junto con cesiones de tierra, fue paulatinamente dando forma al villorrio, luego al poblado y, después, al pueblo.
Sirviéndose de dicha hipótesis -y asumiéndola cierta-, podría decirse que lo público fuera de las ciudades ha surgido desde el comienzo del proceso civilizatorio del Valle Central como un derivado de la hacienda, necesario para atender a una población creciente, sin duda, pero derivado al fin y al cabo. Esta interpretación sobre su origen explicaría la existencia arraigada de un imaginario respecto de lo que un lugar público es y puede ser: siempre asociado a lo oficial y a la representación del Estado en la provincia. Incluso hoy persiste, en la manera de obrar del Estado en estos lugares, un apego al imaginario de la ruralidad asociada a la hacendalidad, que evidencia dificultades para asumir la diversidad y heterogeneidad que ha adquirido esta parte del país (Bengoa, 2008).

En este escenario, pareciera que -descontando la oficialidad de las plazas y calles de los poblados, cuando las hay- lo que aún permanece con un carácter público asociado a su uso, o a su condición colectiva, queda restringido a un conjunto de caminos y sus franjas de borde, a las riberas de ríos y lagos, y a un número de canchas de fútbol que han sido entregadas en comodato a un club o una comunidad ${ }^{8}$.

El asunto que dibuja esta breve revisión, es que este conjunto de elementos- los lugares públicos- no alcanzaría a constituirse como una red, un todo con cierta consistencia; en definitiva no ha habido un proyecto que le otorgue coherencia a los espacios públicos en la ruralidad. Más bien, lo que predominaría es la fragmentación, la dispersión, la ocupación informal, y por consecuencia una condición que denominaremos marginal, de orilla.

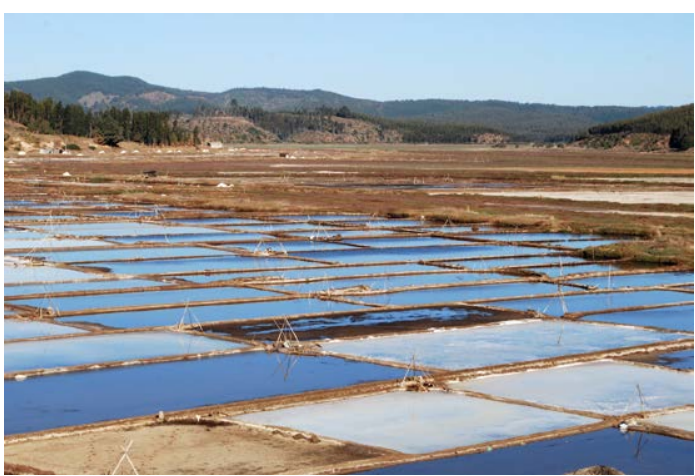

Figura 1 Salineras de Cahuil, 2010. Fuente: Jaime Latorre Soto

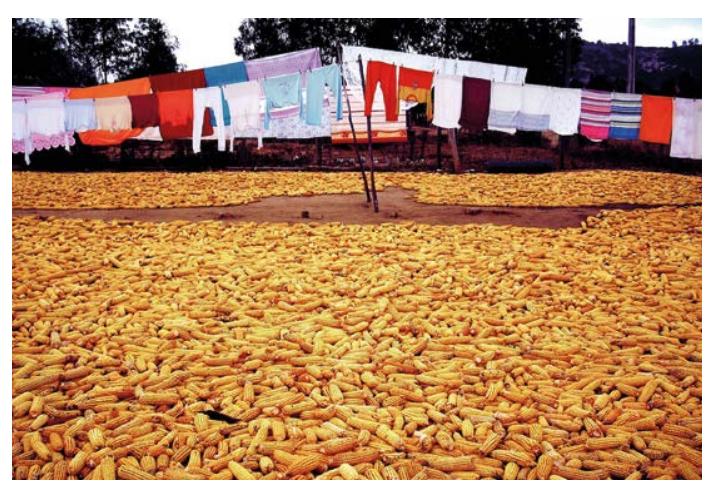

Figura 2 Patio de casa en sector de Pumanque, 2008. Fuente: Jaime Latorre Soto.

[6] Cabe mencionar aquí el caso de Santa Cruz y el valle del río Colchagua. En este sector se han ubicado grandes viñedos que han construido un enclave económico y turístico que instala y refuerza la imagen de la hacienda colonial como producto.

[7] De manera simplificada se afirma que la distinción entre ciudad y poblado radica en que las primeras serán aquellas que han sido fundadas y los segundos, aquellos que surgen de la evolución del poblamiento de las haciendas.

[8] No se ha mencionado en esta lista aquellos terrenos propiedad del fisco que han sido reservados para la preservación ecológica, por cuanto su administración restringe y controla su acceso. 


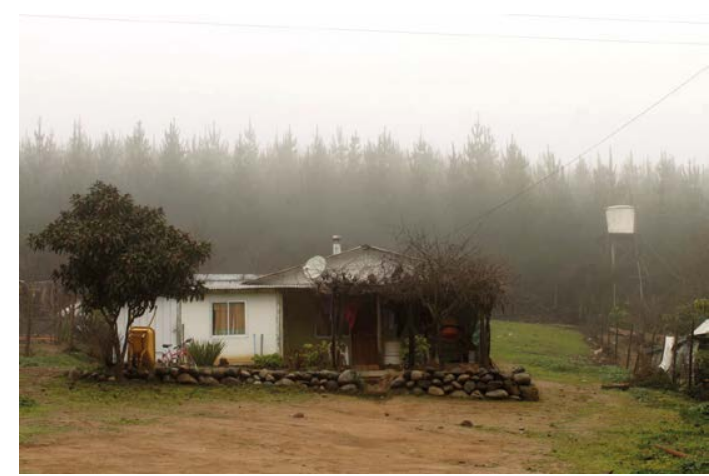

Figura 3 Casas en sector de Caliboro, 2016. Fuente: Natalia Franco Meza.

La distinción esbozada más arriba entre lo público y lo privado, referida a su régimen de propiedad, vale únicamente para distinguir bienes estatales, de bienes privados. Sin embargo, es insuficiente para describir aquellas cualidades espaciales que existen y que refieren al uso que se les da a los espacios, a la accesibilidad, la responsabilidad, la supervisión, la memoria y la identidad, entre otras.

Dicho de otro modo, a menudo el régimen de propiedad de un espacio regula su accesibilidad y su uso, sin embargo $-y$ no menos frecuentemente- existen unas reglas que provienen de ciertas convenciones sociales implícitas o explícitas, que son las que definen en la práctica el sentido de identidad, pertenencia, uso y cuidado de un determinado lugar (Hertzberger, 1991). Ejemplos de aquello abundan, tanto de lugares que siendo públicos son usados para el interés de unos pocos como de otros que, siendo de propiedad privada, forman parte del ámbito de lo colectivo. En ambos casos, la ambigüedad opera a la manera de reclamaciones o interpretaciones que a través del uso reciben ciertos lugares, independientemente de su propiedad: callejones que se vuelven improvisadas canchas de juego, cruces de camino que se convierten en lugares de encuentro, atajos entre los cultivos, escuelas que ofician de centro comunitario, riberas de lago que devienen en playas exclusivas, etc.

Valga lo anterior para precisar el objeto de estudio de este trabajo: aquellos lugares que podríamos denominar públicos por su condición colectiva y la manera de ser habitados, que surgen y se desarrollan de manera más espontánea que planificada. Esto último se suma a lo previamente enunciado: que se encuentran en los márgenes del proceso de modernización del territorio rural y que, sin embargo, son capaces de dar cuenta de la condición contemporánea de ese territorio.

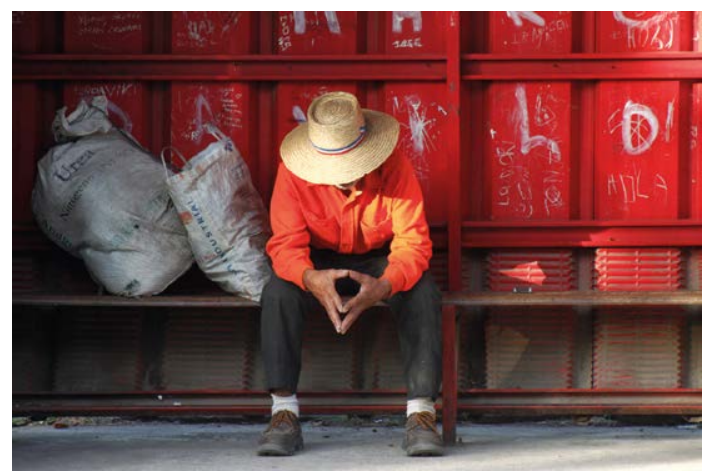

Figura 4 Paradero de bus rural, 2011. Fuente: Héctor Labarca Rocco.

\section{MÉTODO}

La investigación aquí expuesta se ha llevado a cabo dentro de un proceso de enseñanza y aprendizaje -el Taller de Titulación- ${ }^{9}$ en el que se desarrolla un proyecto que se convierte en obra construida. En este proceso, investigación, reflexión y acción se entrelazan de una manera no lineal (Valenzuela, 2015). En otras palabras, se investiga por medio del proyecto y de su ejecución, al tiempo que se utiliza el desarrollo de éste como experimento para develar estructuras físicas y culturales subyacentes en cada lugar.

Una premisa para llevar a cabo esa tarea es la de encontrar oportunidades para un proyecto de interés público, buscando lugares del territorio donde sea posible llevar la arquitectura allí donde no la hay, donde exista la posibilidad de incidir con una obra de pequeño formato y donde existan posibilidades de gestionar recursos y movilizar voluntades para su realización.

Luego de sucesivas versiones del Taller, se ha identificado tres ámbitos en los que se representa aquella condición descrita en la introducción: las orillas de caminos, las orillas de cancha y las orillas de río, los que, dada su recurrencia y similitud, son identificables como tipos.

Cada uno de estos será ilustrado por medio del relato de un caso en el que la obra llevada a cabo da cuenta de aquella condición que les es común y permite reflexionar en torno a las generalidades de su tipo.

El interés de estos trabajos estaría situado en el hecho de que proponen una manera de hacer arquitectura que aspira a la promoción de una comunidad por 


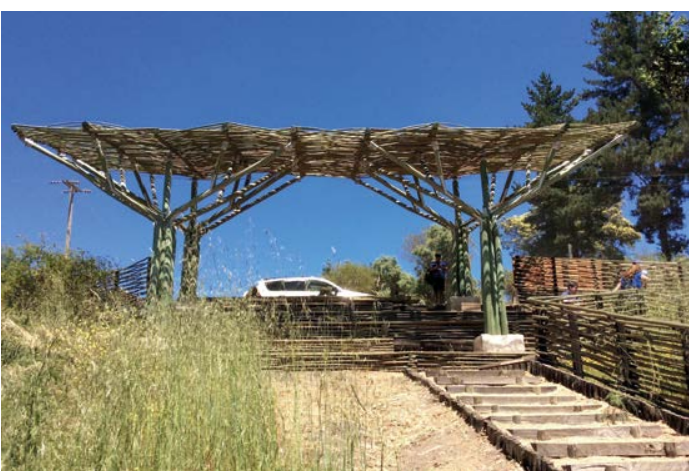

Figura 5 Mirador de la Reserva de Laguna Torca. Fuente: Eduardo Aguirre León.

medio del refuerzo de su identidad a través de una obra pública (Román, 2013). Dicha manera alcanza tanto a problemas de escala territorial como a la escala de lo material, estableciendo una operatividad que atraviesa esas escalas y les da continuidad por medio de un dispositivo.

\section{RESULTADOS}

\section{La orilla de camino}

Muchos de los caminos rurales del valle central aún parecieran estar gobernados por una temporalidad marcada por una velocidad pausada y un tráfico intermitente en una red que comunica poblados y predios con la frecuencia que la actividad agrícola o forestal, la necesidad de servicios y, eventualmente, el turismo lo requiera.

Esta manera dispersa de habitar el territorio alcanza a los lugares públicos, los que surgen como fragmentos allí donde los caminos se ensanchan, se cruzan o se reúnen con algún equipamiento o infraestructura.

En ese régimen temporal y espacial transcurre la vida pública: a orillas de los caminos, entre la espera y el encuentro, tiempo en el que paradero se convierte en plaza ${ }^{10}$.

El sistema hídrico conformado por el Lago Vichuquén la Laguna Torca, la Laguna Los Coipos y la Laguna Agua Dulce, en el secano costero de la región de O'Higgins, es un caso donde se puede observar esta fragmentación de la red de lugares públicos en entornos rurales. De todos ellos, sólo Laguna Torca, al formar parte de una Reserva Nacional" ${ }^{11}$ garantiza el acceso a sus riberas. Las

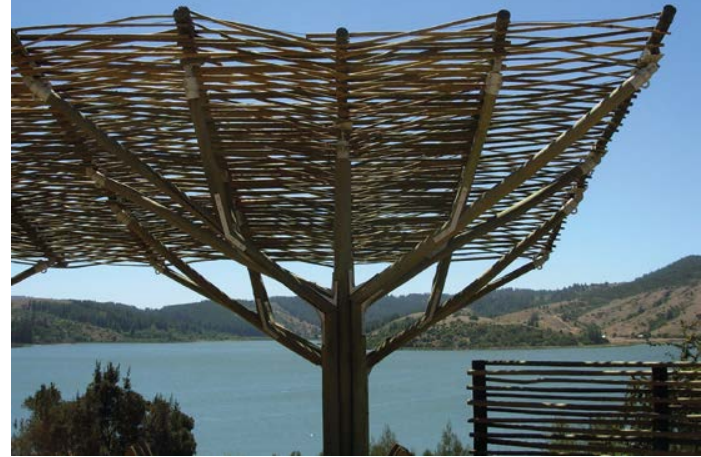

Figura 6 Mirador de la Reserva de Laguna Torca. Fuente: Eugenio Garcés Feliú.

otras lagunas han quedado dentro de predios forestales, y el Lago Vichuquén se caracteriza por una privatización de facto del acceso a sus orillas. La excepción allí es una pequeña playa, Paula, incapaz de dar lugar a la demanda de los habitantes de los pueblos cercanos de acceder al agua del lago.

Atendiendo a ese contexto, el proyecto Mirador de la Reserva de Laguna Torca ${ }^{12}$ funde tres operaciones que, a la manera de una cuña, abren un margen público donde no lo hay: crear el portal de acceso a la Reserva, consolidar la parada del autobús y abrir un mirador hacia el paisaje de la Reserva, haciéndola visible al paseante. Lo conforman, a su vez, tres elementos: un paramento que cierra y ordena, una cubierta que da sombra y enmarca, y una serie de terrazas que contiene el terreno y dan cabida a la espera, el acceso y la contemplación del paisaje de la laguna. En su conjunto, el mirador da cuenta de la escala del paisaje y lo conecta con el camino público.

En su construcción, la cubierta y paramentos del acceso reinterpretan la manera popular de construcción de cercos por medio de varas flectadas, estableciendo de este modo una continuidad material con el paisaje del entorno.

Concurren en su resolución diversas voluntades: la de CONAF, a la manera de contraparte, apoyo técnico y provisión de materiales; la Municipal, por medio de la mano de obra; y la de la comunidad a la que atiende, mediante un apoyo en la gestión de recursos.

La obra bien puede entenderse como un dispositivo que da cuenta de una determinada condición territorial y la refleja. Luego, se constituye en germen de alteración del territorio, ensanchando el margen que queda a la orilla del camino y ampliando el imaginario de lo público en la zona.

[10] El paradero-plaza es una idea que surge en el Taller de titulación, en el año 2007, al reparar en la condición de lugar de encuentro que tienen algunas paradas de autobús en localidades rurales y la posibilidad de proyectarlas a la manera de pequeñas plazas, lo que as connota en tanto lugares.

[11] La Reserva Nacional Laguna Torca se crea en el año 1985 para preservar el ecosistema húmedo más importante de la zona central del país, protegiendo así a una gran cantidad de avifauna en peligro de extinción

[12] Proyecto Mirador de Laguna Torca. Obra de titulación de Andrés Morán (2012). Escuela de Arquitectura, Universidad de Talca. 

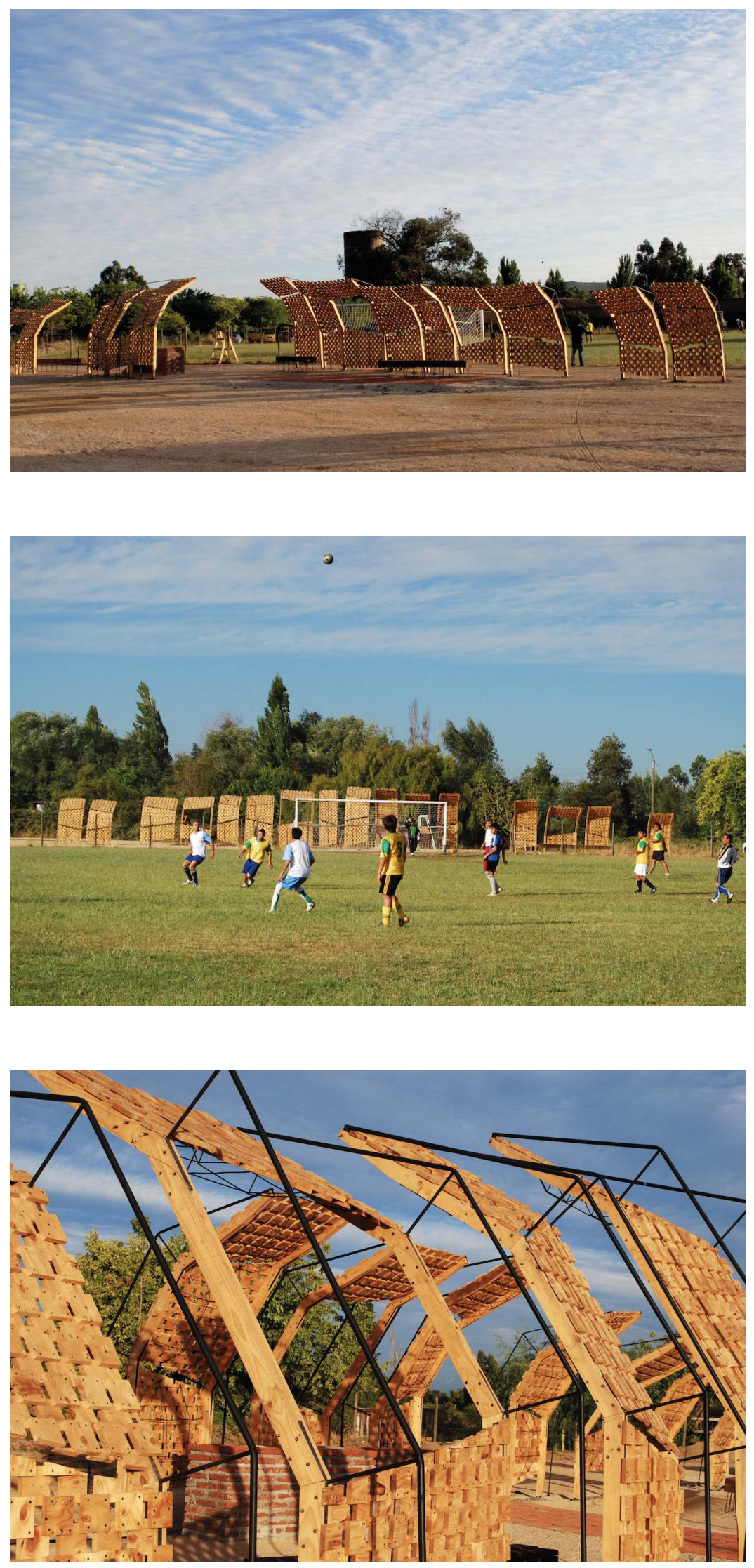

Figura 7 Observatorio Numpay, Maule, 2009. Fuente: Jaime Latorre Soto. 


\section{La orilla de cancha}

Muchas canchas de fútbol rurales son un remanente, podría decirse, de las organizaciones que surgieran o se consolidaran en el período de la reforma agraria.

Usualmente, su status legal es el de un terreno común o en comodato de una junta de vecinos o un club deportivo. Sin embargo, en la práctica, las canchas son escenario de un sinfín de actividades que las convierten tan pronto en sede social como en lugar de matrimonios, graduaciones, actos escolares, bingos, ramada dieciochera o el improvisado lugar de la posta. La cancha rural, espacio de grandes dimensiones, puede concebirse como la plaza de escala territorial (Román, 2013) ${ }^{13}$.

La cancha rural de Numpay, en Unihue, se ubica entre el borde sur de Talca y el pueblo de Maule, en una inminente conurbación poblada por parcelas de agrado, cultivos agrícolas, escuelas, moteles y clubes de verano, entre otros; los que conforman un paisaje en acelerada transformación con algunas trazas del orden agrícola previo a la expansión urbana.

En torno a la cancha, por el oriente, existe una hilera de viviendas, las que fueran construidas como parte de los programas de subsidio del Estado para vivienda rural hace unos veinte años atrás. Por el sur, el paisaje está dominado por un gran silo de hormigón, la antigua casona y las bodegas, construcciones en adobe y teja, cuyas dimensiones permiten inferir que atendieron a un fundo de gran tamaño, el que en algún momento fuera subdividido permitiendo la instalación de la hilera de viviendas campesinas que conforman el lado poniente de la cancha. Este último, se muestra más verde que los otros, debido a los frutales y chacras que cada casa tiene para su subsistencia.

Sólo la orilla norte de la cancha permanecía vacante al momento de desarrollar el proyecto, a la espera de que alguna vez se hiciera la multicancha, la sede social de la junta de vecinos o un suelo que facilitara el baratillo y el asado que acompañan cada encuentro entre el equipo local y el adversario visitante de turno.

El Observatorio Numpay ${ }^{14}$ es una intervención que viene a completar el conjunto de elementos que, a la sazón, permanecía incompleto, ofreciendo una interpretación de lo que podría ser el estadio rural, que se aleja de la idea de gradería y camarín. Se plantea a la manera de soporte, de plazoleta, de espacio abierto a la interpretación de la comunidad para su uso en todas aquellas ocasiones en las que, además del fútbol de los domingos, pueda ser utilizado. Para su realización, se reúne el apoyo del Club deportivo Numpay y la organización vecinal, tanto para la participación en el diseño como para la ejecución; y también del Municipio, que contribuye con maquinaria y materiales, y aserraderos locales.
Una serie de paramentos construidos con despuntes de madera dan escala, constituyen espalda y soporte espacial y material, al tiempo que dan sombra para la reunión. Dos suelos de ladrillo hecho a mano marcan el paso de las personas hacia otros sitios e indican los lugares para la ubicación de un baratillo y una asadera. En suma, la ocupación del sitio anticipa la posible ubicación de la multicancha y de la sede social, cuando sea el momento de su llegada.

De este modo, la intervención ordena y da escala al conjunto, al tiempo que devela una estructura social y cultural existente en el territorio ${ }^{15}$.

\section{A orilla de río}

Se puede afirmar que, así como en las ciudades cabecera del Valle Central se habita en estrecha relación con la carretera Norte Sur, en la ruralidad del secano y de la cordillera se lo hace en relación con las cuencas de los ríos, cuyos cursos, que atraviesan el Chile Central en un recorrido de cordillera a mar, determinaron durante los siglos XVIII y XIX las formas de habitar el territorio en una lógica espacial transversal. Esta contribuyó al dibujo de una identidad que posteriormente fuera transformada por el sometimiento a una lógica longitudinal asociada a la infraestructura y al tránsito norte-sur, predominante hasta ahora (Núñez, 2012).

Sin embargo, subyace en las áreas más lejanas a la carretera 5 Sur una relación identitaria de las localidades con la cuenca en la que se inscriben, así como la de los habitantes con la orilla de sus ríos y su régimen de sequías y crecidas. Refuerza esta condición el hecho de que la conectividad longitudinal ha tardado en llegar a muchas de estas zonas.

Es natural, entonces, que los habitantes de las localidades de cuenca desde siempre hayan hecho suyas las riberas públicas de los ríos, a la manera de lugares de descanso de las labores agrícolas, de paseos de tarde, de espontáneos balnearios donde capear el calor del verano, etc.

La huerta del Mataquito es una de aquellas localidades. De vocación agrícola, se ubica en la ribera norte del río del mismo nombre, extendiéndose con la forma de pueblo de calle larga, entre ladera de cerro y borde de río, para encontrar en las tierras irrigadas su sustento y razón de ser.

A un costado del puente nuevo, rodeando el remanente de hormigón de las bases del antiguo puente que fue llevado por alguna de las crecidas, es posible acercarse a mirar el curso del río y bajar a su orilla, tal como acusan algunos indicios, improvisados escalones, vestigios de fogatas, etc.

En este lugar, el proyecto Tres pausas ${ }^{16}$ da cuenta de esta condición de pequeño balneario espontáneo, descubriendo en los vestigios de su uso una estructura preexistente, que luego la propuesta viene a reforzar, develar y consolidar.

[13] La plaza de escala territorial es una idea que surge en la Escuela de Arquitectura de la Universidad de Talca, previa al desarrollo del Taller de Obra realizado en el año 2012, cuyo tema fuera el "Todo es cancha". La idea forma parte del enunciado del taller, que ordena el trabajo que llevan a cabo varios equipos de profesores y estudiantes en diversas canchas en el territorio del Maule.

[14] Observatorio Numpay. Obra de titulación de Ignacio Loyola (2009). Escuela de Arquitectura, Universidad de Talca.

[15] El terremoto de 2010 dañó considerablemente la casona del fundó de Numpay e igualmente el silo de grano. Tiempo después, el proyecto fue removido para instalar en su lugar una plazoleta con máquinas de ejercicios y una sede social.

[16] Tres pausas. Obra de titulación de Francisca Acevedo (2015). Escuela de Arquitectura, Universidad de Talca. 


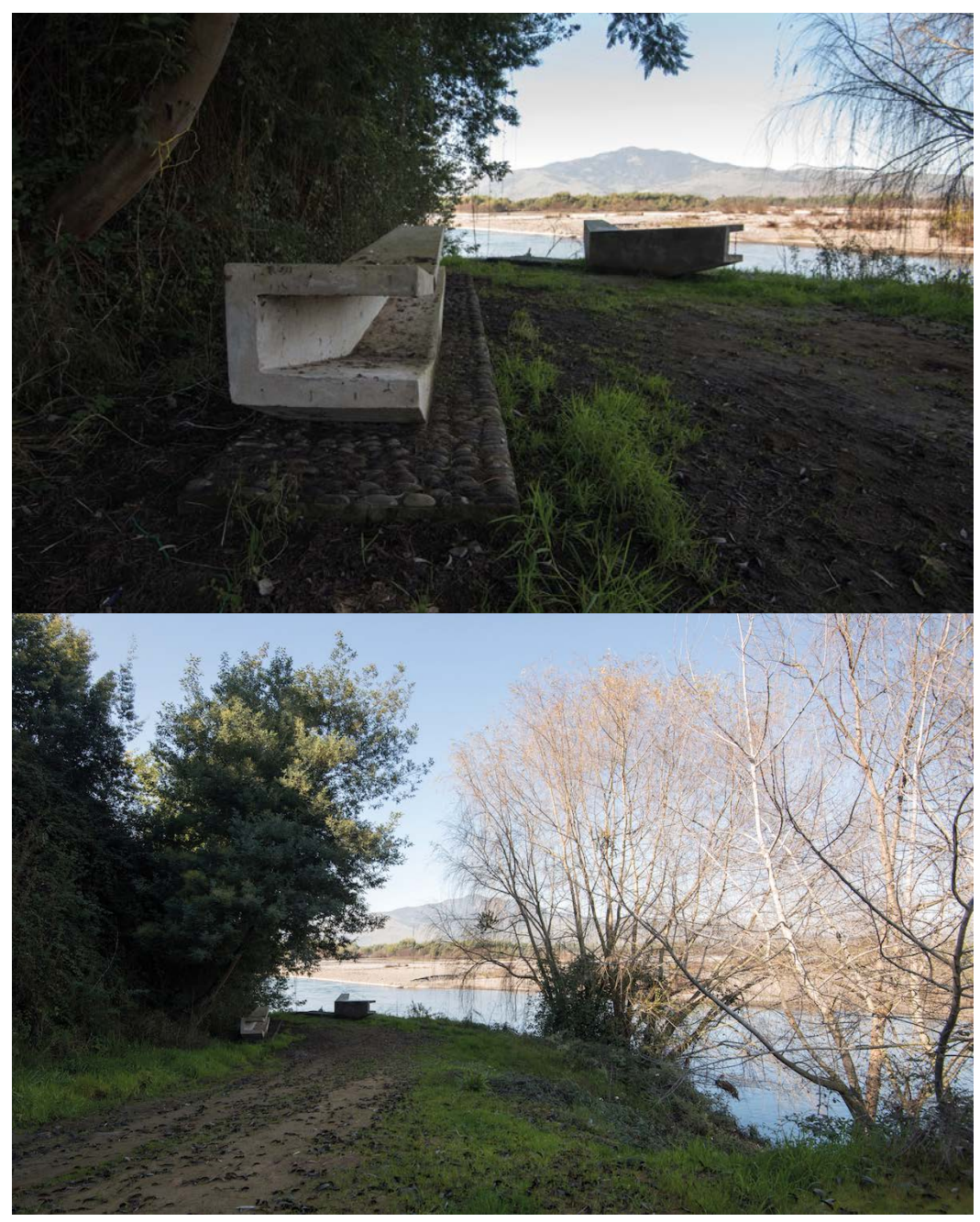

Figura 8 Balneario Tres pausas, La huerta de Mataquito, 2016. Fuente: Felipe Figueroa.

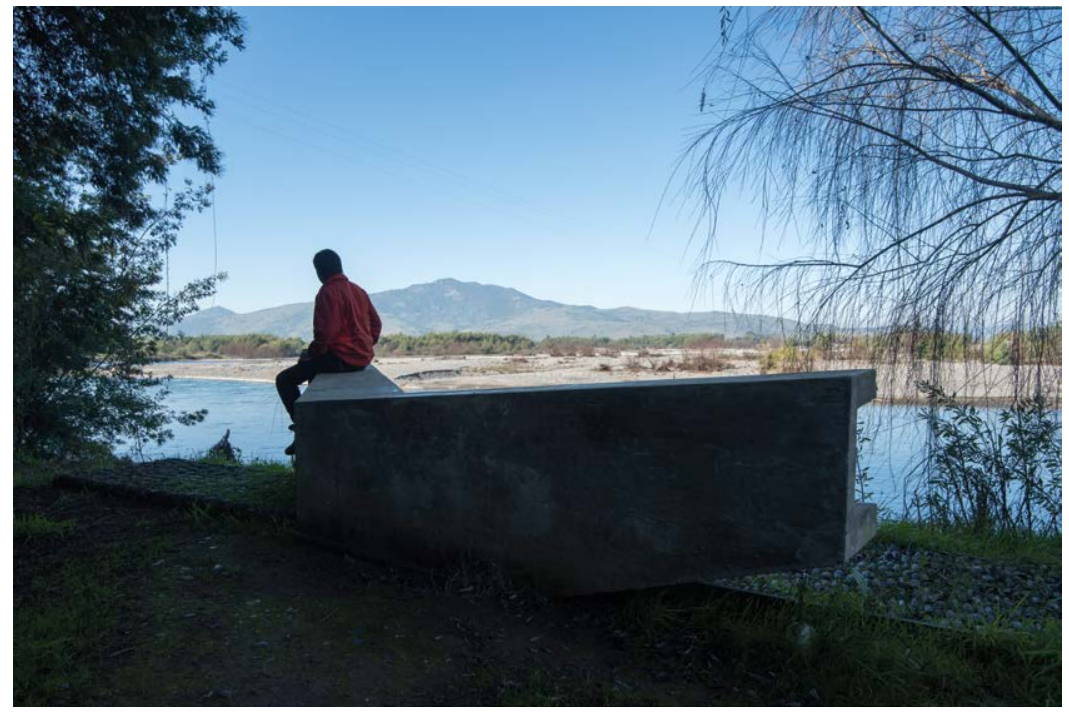

Figura 9 Balneario Tres pausas, La huerta de Mataquito, 2016. Fuente: Eduardo Aguirre León. 
Se instala tres cuerpos macizos de hormigón, acompañados de una alfombra de piedra huevillo cada uno, lo suficientemente distantes como para abarcar el espacio geográfico de la hondonada y marcar los tres puntos que dan cuenta del programa de usos: uno frente a la gruta de un santo popular, otro a la sombra de un aromo y un último aproximado a la orilla, en voladizo. El hormigón armado y la piedra de río otorgan a la intervención una continuidad material con el entorno, lo cual sumado a la manera de instalar sus piezas genera que, al cabo de un año, se vea integrada al lugar y consiga evocar su condición de vestigio develada en un inicio.

Concurren en la materialización de este proyecto los vecinos, quienes habitualmente usan el lugar y lo cuidan, y contribuyen a gestionar el involucramiento del municipio que, a su vez, aporta con maquinaria, materiales y mano de obra, y compromete la mantención del sitio.

El proyecto opera en el lugar con una dinámica similar a la de un mensaje enviado en una botella: pretende ser encontrado por quienes van a pasar la tarde mirando el río, y ser interpretado. Así, con cierto anonimato, el lugar expresa la condición de margen de estos balnearios, que son de todos y son de nadie, y cuya vida pareciera transcurrir en la parte trasera del territorio.

\section{CONCLUSIONES}

Hay algo común en los trabajos aquí presentados: entender el proyecto como vehículo para decapar, para hacer aparecer, revelar y poner en valor estructuras presentes en la ruralidad, estructuras blandas, por llamarlas de algún modo.

La manera de hacer supone, para el arquitecto, operar atendiendo al territorio en diversas escalas, en un proceso que no es lineal. Respecto de la mayor escala, se trata de identificar un punto en un sistema territorial, un lugar estratégico donde intervenir para construir relaciones nuevas o re-establecer las anteriores. Respecto de la escala del paisaje, se busca que un proyecto de pequeño tamaño se sume a órdenes existentes por medio de su configuración en el espacio, cosa que luego alcanza al detalle, el que por medio de la definición bien puede construir un puente de continuidad material con su entorno y de esa forma, generar cierta resonancia en él.

Lo anterior permite afirmar que el proyecto de arquitectura puede ser un agente de alteración del territorio, contribuyendo a la renovación del imaginario de lo público en la ruralidad.

Los proyectos expuestos han permitido que las comunidades a las que sirvieron puedan ver reflejados en ellos su forma de habitar en común lugares que, a través de la intervención, son develados o reafirmados en su sentido y uso. El devenir en el tiempo que estos lugares exhiben afirma lo dicho, por cuanto han sido mantenidos, reparados o reemplazados por infraestructuras más duraderas.

\section{REFERENCIAS BIBLIOGRÁFICAS}

BENGOA, José. Valle Central, imaginarios, interpretaciones, ensoñaciones. Revista de la Escuela de Arquitectura de la Universidad de Talca, 2008, n² 2, pp.18-25.

BENGOA, José. Introducción. Memoria, patrimonio y terremoto. En: Aguilera, Iván; Bengoa, José; Daber, Yuri, Delgado, Cecilia; Mora, Cristal; Planells, Diego; Silva, Nicolás; Sotomayor, Joan y Valdivia, Carol. Valle Central, memorias, patrimonio y terremoto en haciendas y pueblos de Chile Central. 1era edición. Santiago: Editorial Catalonia, 2012, pp. 15-27.

HERTZBERGER, Herman. Lessons for students in Architecture. Rotterdam: 010, 1991.

MELLADO, Justo Pastor. El montaje de una enseñanza. En: Uribe, José Luis y Girborio, Andrea (eds.). Talca, cuestión de Educación. 1era edición. México: Arquine, 2013, pp. 186-199.

NÚÑEZ, Andrés. El país de las cuencas: fronteras en movimiento e imaginarios territoriales en la construcción de la nación. Chile, siglos XVIII-XIX. Documento presentado en el Segundo Coloquio Internacional de Geocrítica: Las independencias y construcción de estados nacionales: poder, territorialización y socialización, siglos XIX y XX. Bogotá: Universidad Nacional de Colombia, 2012.

ROMÁN, Juan. Taller de agosto. En: Uribe, José Luis y Girborio, Andrea (eds.). Talca, cuestión de Educación. 1era edición. México: Arquine, 2013, p. 63.

VALENZUELA, Germán. Experimento y crítica en la formación del arquitecto. Summa+, 2015, n 146, p.128.

ZUSMAN, Perla. Perspectivas críticas del paisaje en la cultura contemporánea. En: Nogué, Joan (ed.). El paisaje en la cultura contemporánea. 1era edición. España: Biblioteca Nueva, 2008, pp. 275-296. 